\title{
ASSESSMENT OF POSSIB ILITIES TO USE THERMAL IMAGING CAMERAS FOR AIR TRAFFIC CONTROL
}

The character of missions and conditions in which they are carried out by military unmanned aerial vehicles are usually special and difficult. This causes a necessity to provide support for their missions, especially with regard to checking their condition on the controlled or autonomic flight path, especially during landing and take-off operations.

This paper offers an account of an experiment and an attempt of assessing usefulness of thermal imaging cameras for controlling flights of aerial vehicles, mainly in areas of airdromes and approach paths.

\section{Keywords:}

thermal imaging cameras, landing systems, unmanned aerial vehicles.

\section{INTRODUCTION}

In manned aerial vehicles a human being is the main element of the flight control system. They visually analyze data from sensors and use it to correct the flight. A pilot (navigator) also observes the external world around the vehicle, which allows him/her to better understand the flight conditions.

Flight-support vision systems installed in aerial vehicles most often consist of cameras working in human vision and infrared ranges, and laser altitude control systems. Complementarity of vision systems with regard to parameters and the spectrum range of performance considerably extends the range of their applications and enhances their significance as instruments for remote acquisition of visual data used to support flight control, and also used, e.g. by the Polish Navy aviation units to carry out reconnaissance and coordination as well SAR support missions. 
Unmanned aerial vehicles (UAV) are most often remotely controlled or autonomous, pre-programmed platforms used to carry various sensors, especially thermal ones, and more and more often weapons. In autonomous unmanned vehicles the absence of a pilot requires developing automatic flight control systems. Use of on-board computers with dedicated software enables the UAV to carry out a variety of missions, including, among others:

- navigation of an UAV;

- monitoring the course of events and object identification;

- supervision over landing and take-off operations.

The thermal imaging systems have also been widely used in ground-based air traffic control systems. Visual monitoring is commonly used in aerodromes, where it provides automatic tracking of people in terminals and vehicles, as well as aircraft in aprons, taxiways or runways.

In recent years visual based landing have become important in military and civilian practice. At present, avionics are primarily used in radionavigation systems. Belong to them: instrumental landing system, precision approach radar, marker beacon and others. However, their use is associated with significant emission of electromagnetic fields. Vision systems are passive systems, increasing their meaning in the military sense. The problems associated with the use of vision in landing systems are presented in [Kong, Zhou, Zhang, 2014]. In [Kong et al., 2013] stereovision system based on IR cameras is presented, whereas in [Kong et al., 2014] authors presented a baseline system leaning on two separate sets of PTU integrated with visible light camera on both sides of the runway. However, in this document, we present a system based on a single thermal imaging camera.

\section{THE CHARACTERISTICS OF VISION SYSTEMS}

Progress in electronic an IT technologies have contributed largely to the development of vision monitoring and control systems based on image recognition. The possibility to record high-resolution images, instantly analyze them, and/or transmit them to a control station ensures reduction in time needed to make a decision or automatic response of the system. An additional important feature of modern vision systems is the possibility to use techniques and algorithms eliminating the necessity to operate them by an operator, who can perform only the control function, 
e.g. during the whole control process of the take-off and landing operation as well as during aircraft movement at the airport. It is integrated optoelectronic heads equipped with sets of various sensors and cameras that become the main element of every system. Cameras working in the human vision and infrared ranges are most often used. Owing to inclusion of the infrared range in the surveillance system it becomes less susceptible to interference caused by atmospheric phenomena (fog, rain), by light (day, night), and artificial interference.

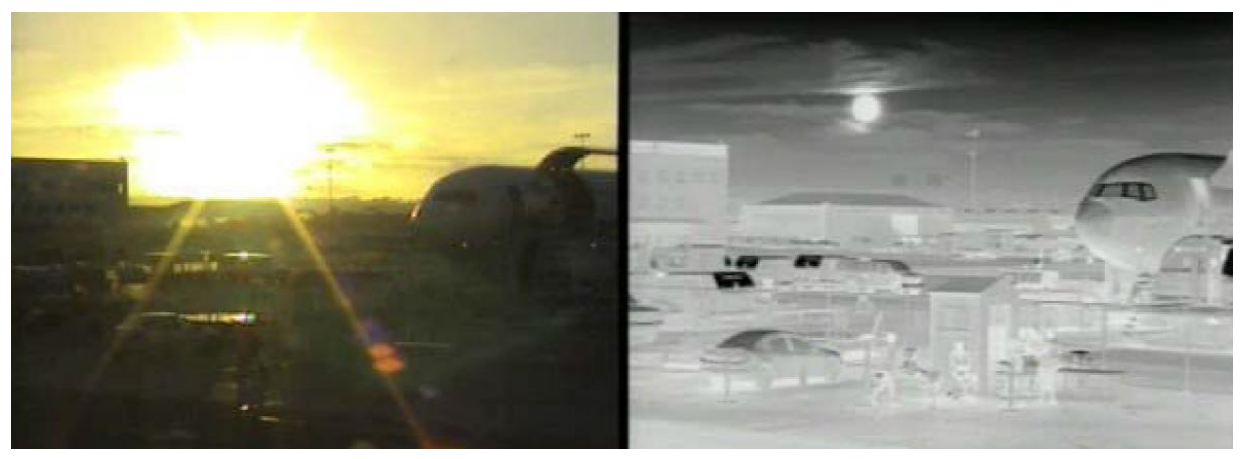

Fig. 1. An example of glaring effect of sunlight on an image recorded with a camera working in the human vision range (right) and in the infrared range (left) [http://www.ttcs.es/component/ tags/tag/camaras-de-seguridad.html?start=20 (access 12.05.2016)]

An additional piece of equipment installed in heads is a laser rangefinder allowing for precise measurement of ranges to objects appearing in the monitored space or measurement of flight altitude. However, its use with regard to manned aircraft is limited due to safety of crews.

Most of vision cameras available and used at present are characterized by very high sensitivity and resolution, which, when taking in to consideration the two distinguished spectral ranges, ensures acquisition of images which after analyses are a source of a lot of information on the observed objects and their surroundings as well as on the events in which they are involved.

\section{THERMAL IMAGE OF AN AERIAL VEHICLE}

In conditions of limited visibility, including night, observation of aerial vehicles is possible with use of thermal imaging cameras, converting heat energy, 
emitted or reflected from the observed objects into a visible image. In the case of aerial vehicles the main sources of emitted heat energy are:

- working engines and elements of propulsion;

- exhaust gases;

- fuselage and lift elements — wings, stabilizers, propellers, etc.

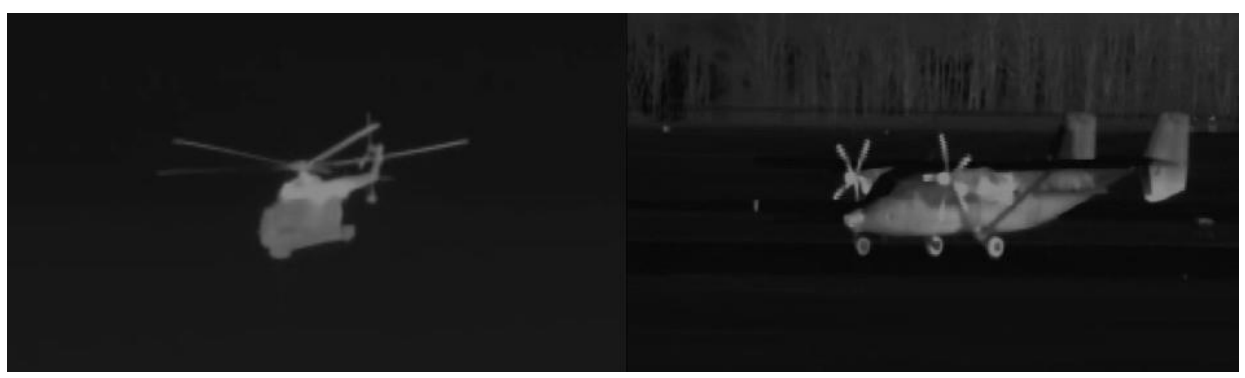

Fig. 2. An example of a thermal image of an aerial vehicle in shades of grey

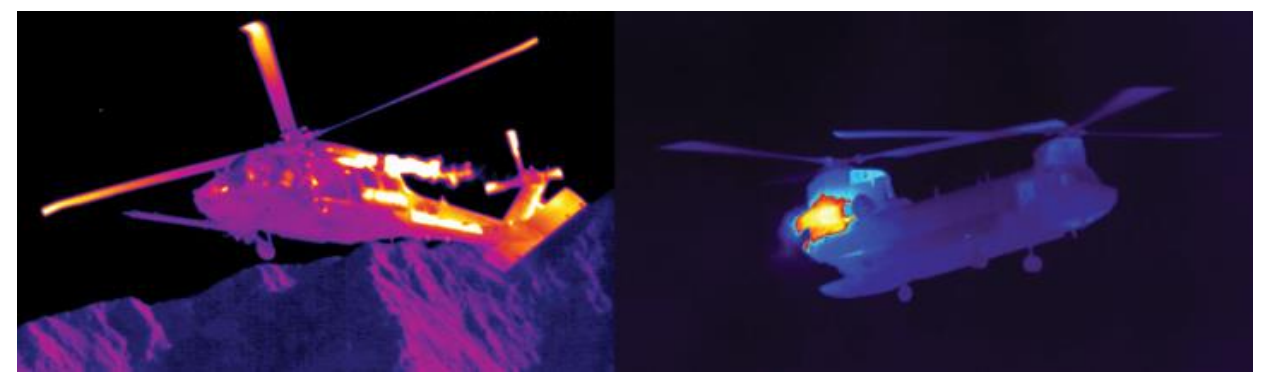

Fig. 3. An example of a thermal image of an aerial vehicle in color [https://www.osa-opn.org/ opn/media/images/articles/0411/Features/FeatureImages/feature1-fig1.jpg; https://www.army.mil/e2/-images/2008/10/02/23294/size0-army.mil-2008-10-03-145322.jpg (access 12.05.2016)]

The amount of heat radiation energy recorded by thermal imaging cameras is the function of temperature and radiation properties of an aerial vehicle. Radiation properties of the surface decide about its capability to reflect and absorb, and then return heat energy to the ambience and depend on: shape, size and kind of surface. Hence, the conditions presented allow for assuming that the most important features of an aerial vehicle enabling its effective observance in the infrared range are as follows:

- geometric dimensions of the vehicle;

- shape and inclination angles of planes making the form of the object; 
- arrangement of engines and moving propulsion elements;

- temperature magnitude at characteristic points and their distribution across the surface of the observed object.

In order to build dedicated vision systems working in the infrared range it is necessary to determine the conditions in which they work, including: temperature magnitudes characteristic of the observed objects, ambient conditions, expected range of observation, and additional instrumentation allowing for determination of ranges, localization in space. This will enable, among others, the optimum choice of and matching the camera features, including the choice of spectral sensitivity range, optic parameters and image recording speed. As a result, a capability will be obtained to record thermal images of good quality and to fast process them, useful in the system being built [Milewski, 2009].

The capability of the system to monitor and control air traffic will be then evaluated on the basis of the possibility to detect them in specific conditions of observation, and then the possibility to track them on the basis of distinguished thermal, geometric and dynamic properties. The element integrating all the elements of the system being designed will be dedicated software which allows for carrying out missions in the automated manner.

\section{THE CONCEPT OF VISION TRAFFIC CONTROL SYSTEM ON APPROACH PATHS}

The base for developing the concept is determination of the required field of vision (FOV) size in the observation system and its location in the aerodrome area. The geometric dimensions and direction of observation will determine:

- size and boundaries of the imaged space section, which means recorded images of objects and their orientation in relations to the aerodrome;

- background against which this task is carried out;

- geometric resolution of an image;

- thermal sensitivity of the system.

Detection and localization of the object in the recorded image will be conditioned by two criteria (so called thresholds), determined by means geometric and thermal parameters of the system. Within the infrared range, the physical 
dependence, determining boundary capabilities to detect an object in the observed scene are determined by dependence

$$
S N R_{D}=\frac{\Delta T \tau(\lambda)}{N E T D}=1
$$

where:

$S N R_{D}$ - signal to noise ratio required to detect an object,

$\Delta T$ - object-noise thermal contrast,

$\tau(\lambda) \quad$ - signal damping in atmosphere coefficient,

NETD — Noise Equivalent Temperature Difference.

Graphic interpretation of the discussed process is presented in Figure 4.

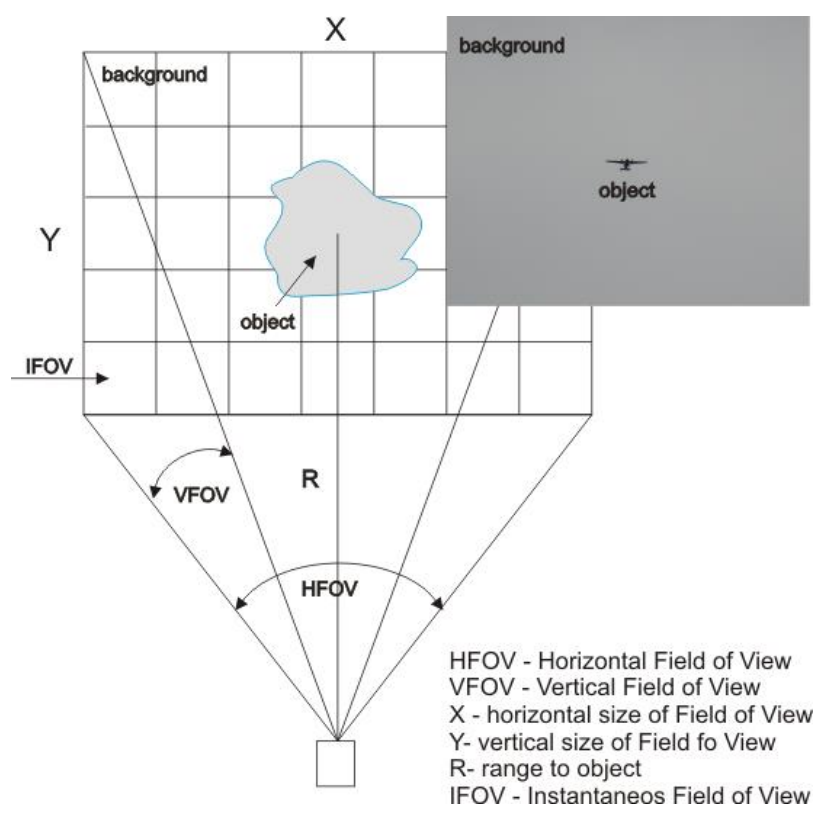

Fig. 4. Graphic interpretation of the process of object detection in a thermal image

In the field of knowledge such as image recognition, methods used to detect objects are most often based on known and presented in the literature algorithms, e.g. [8]:

- image segmentation;

- Harris algorithm;

- background modeling. 
In most cases algorithms dedicated to specific applications use analytically and/or experimentally determined so called sensitivity thresholds of the observation system, tuned to observation conditions (noise) and features of the searched for object. This ensures enhanced effectiveness of the algorithm as a result of reduction in time necessary to identify object/interference, i.e. weather the signal detected from the background is the signal characteristic of the aerial vehicle searched for or is it local interference.

Detection of an aerial vehicle initiates the process of tracking it. In this process, following analyses of successive images and changes in specific features (object properties) it will be possible to determine components of its movement, such as: course, speed, altitude. They will be used to work out commands to make corrections in the flight. The diagram of a ground-based flight control station is presented in Figure 5.

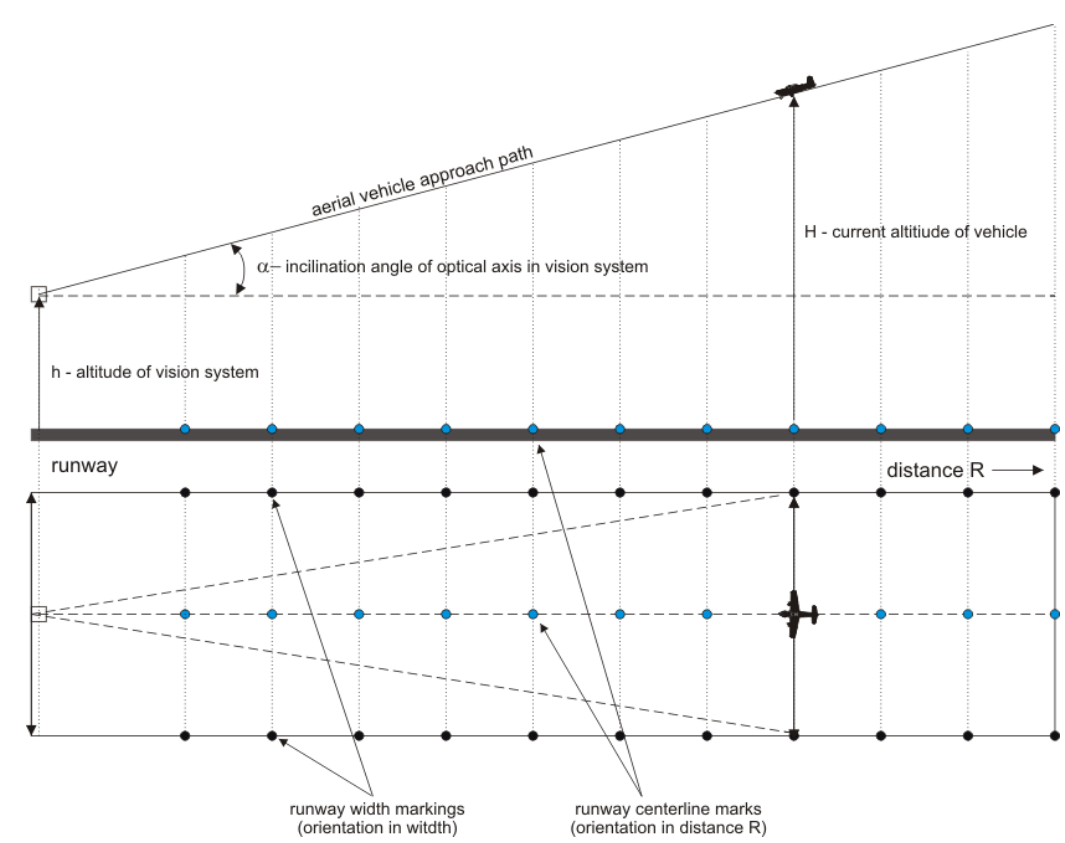

Fig. 5. The concept of organization and equipment for a ground-based station of vision flight control of aerial vehicles

The presented concept of air traffic control assumes that the most important is to determine input data and assumptions relating to properties of aerial vehicles, equipment and organization of the measuring system and conditions for 
its performance. In the next stage of investigations, after known and available algorithms of detecting and tracking have been employed, it is planned to test the station in order to prove its effectiveness or to verify the assumptions.

\section{THE EXPERIMENT}

The optoelectronic head from the artillery system BLENDA operated by 43 Naval Aviation Station was added to the tests stand. The optoelectronic head is equipped with instrumentation which ensures detecting and tracking aerial objects. It is composed of a thermal imaging camera, daylight TV camera, laser rangefinder and IFF device (Identification Friend or Foe System).

The experiment was preceded by selection of objects characteristic of the Babie Doły aerodrome, flight paths and approach paths for An-28 Bryza plane and W-3 Sokół helicopter. It was also found out that in the case of the selected objects elements it is engines and revolving propellers that are most detectable for infrared sensors, i.e. elements characteristic and useful in the process of flight control.

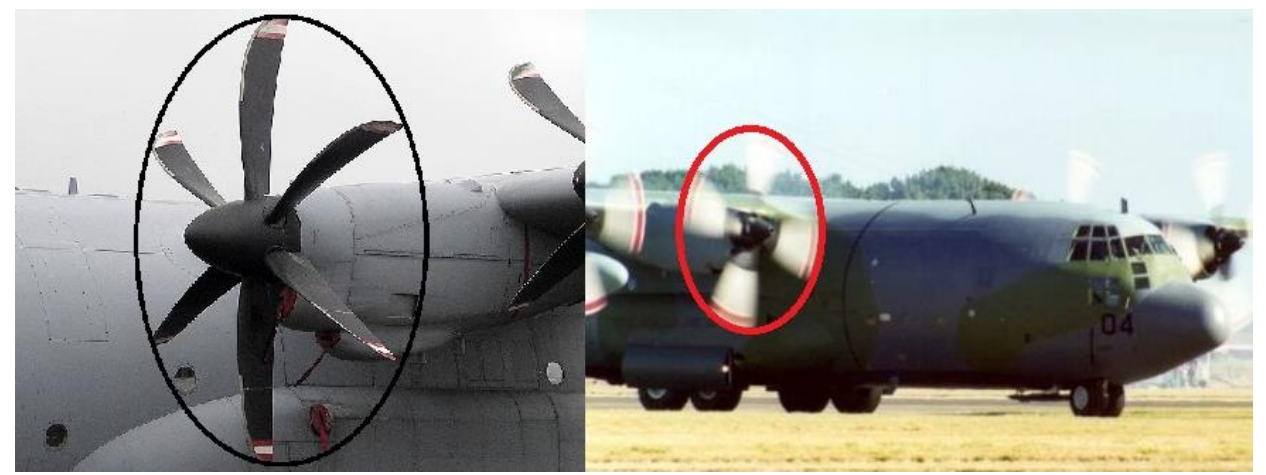

Fig. 6. Observation of a revolving propeller at different angles

[https://upload.wikimedia.org/wikipedia/commons/thumb/c/c3/Hercules.propeller.arp.jpg/ 500px-Hercules.propeller.arp.jpg; [http://www.aerospaceweb.org/aircraft/transport-m/c130/c130_

02.jpg (access 12.05.2016)]

The base for the adopted assumptions is the fact that an engine with revolving propellers is a perfect source of heat energy - well mapped in a thermal image. In addition the revolving propeller designates a circle, which ensures the possibility of determining its diameter even during observation from different angles. This property was used to determine the dimensions of the aerial vehicle. 

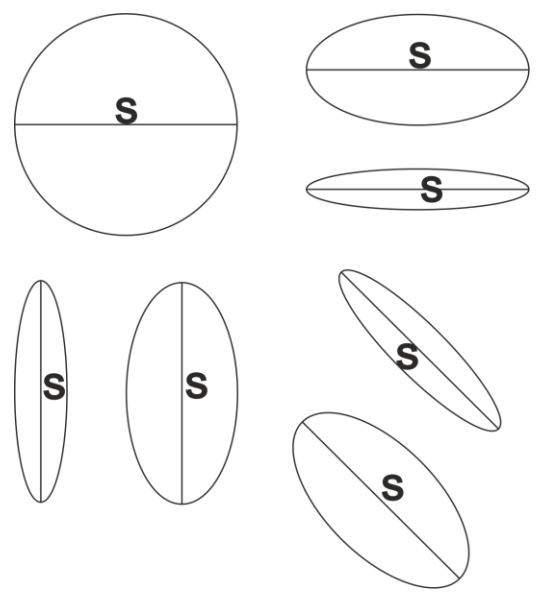

Fig. 7. Observation of a revolving propeller from different angles

The first stage of the experiment was dedicated to evaluating the possibility to determine true dimensions of the aerial vehicle based on the radius of the revolving propeller. The correctness of the adopted assumption was proved through measuring the basic thermal and geometric parameters of the Bryza An-28 plane and an analysis of thermal images recorded with the thermal imaging camera. Figures 8 and 9 illustrate the adopted measurement methodology in two variants of characteristic plane sizes.

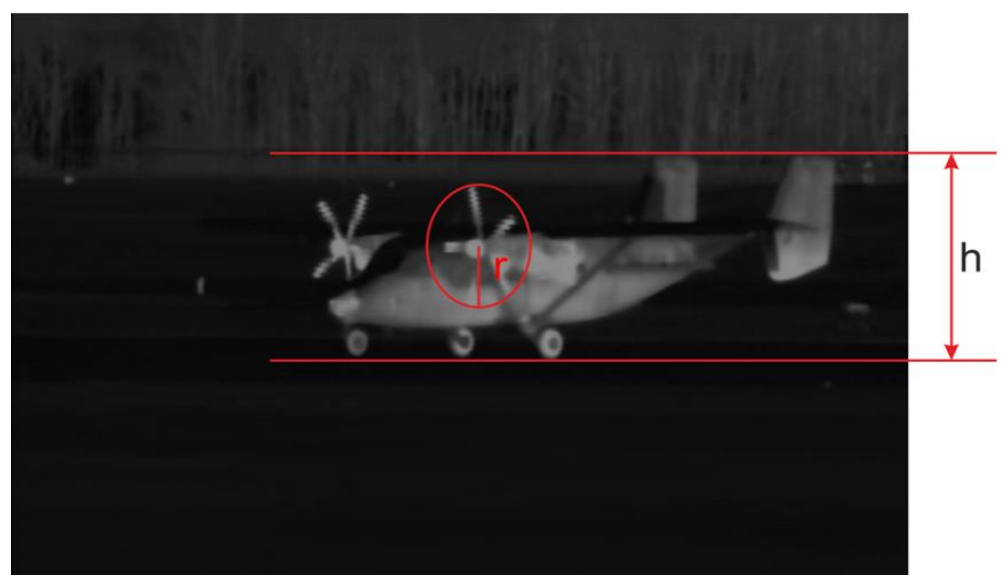

Fig. 8. A thermal image of the AN-28 plane 
The methodology also includes comparing the determined plane size indicators - image-related and true — when determining the plane height, obtained on the basis of dependence:

$$
\frac{r}{h}=\frac{R}{H} ; \quad \frac{12.5[\mathrm{~mm}]}{43.441[\mathrm{~mm}]}=\frac{1.410[\mathrm{~m}]}{4.900[\mathrm{~m}]} ; \quad 0.28775 \approx 0.28776,
$$

where:

$r$ - length of propeller in image (for resolution $300 \mathrm{dpi}$ ),

$h$ - height of plane in image,

$R$ - real length of propeller An-28 - 1.41 [m],

$H$ - real height of An-28 - 4.9 [m].

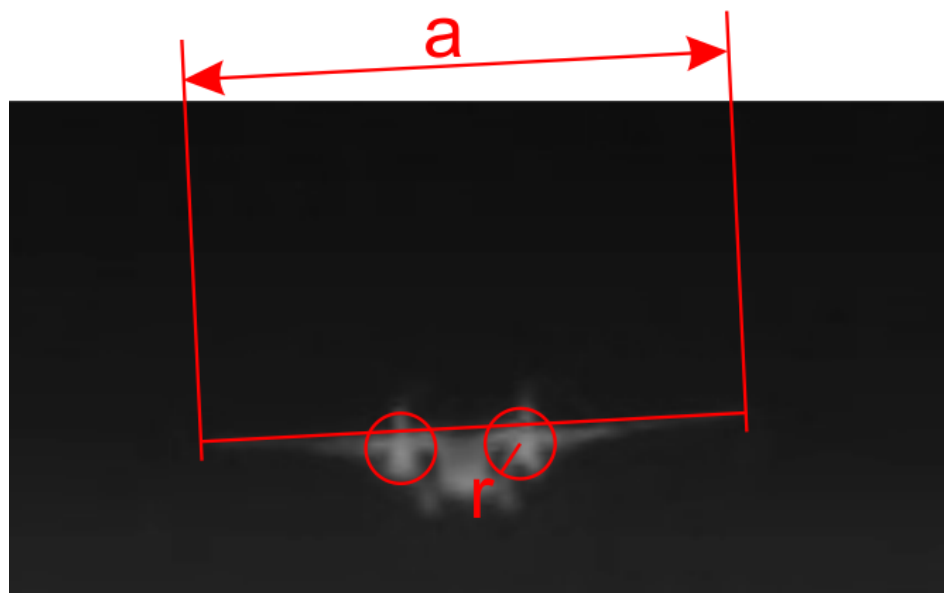

Fig. 9. An example of thermal image of aerial vehicle in color

The comparison of the determined plane size indicators — image-related and true, when determining wing span, obtained on the basis of dependence:

$$
\frac{r}{a}=\frac{R}{A} ; \quad \frac{4.2[\mathrm{~mm}]}{32.711[\mathrm{~mm}]}=\frac{1.410[\mathrm{~m}]}{22.3[\mathrm{~m}]} ; \quad 0.0642 \approx 0.06323,
$$

where:

$r$ - propeller length in image,

$a$ - wing span in image,

$R$ - real propeller length of An-28 - 1.41 [m],

$A$ - real wing span of An-28 - $22.3[\mathrm{~m}]$. 
The calculation of the aerial vehicle size indicators with a method based on calculating the ratio of propeller radius in the thermal image to the real radius, and the plane dimensions in the image to the real dimensions indicates that the proposed method generates small errors and can be used for flight control. The size of the plane determined with this method - in the measurement system having known parameters offers a possibility to determine the altitude of the plane over the runway, going off the course or going off approach paths in the course of landing.

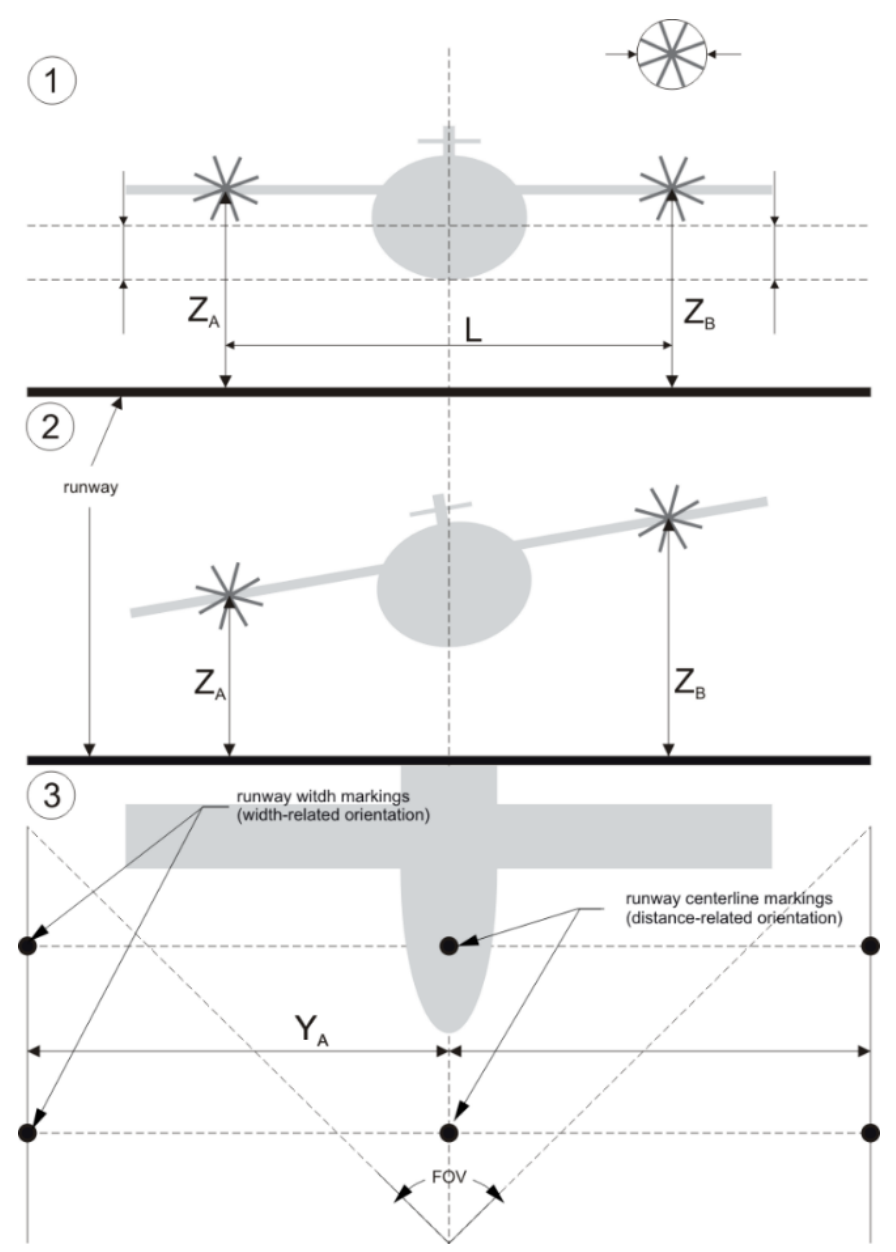

Fig. 10. Graphic interpretation of using the described method for determining aerial vehicle size indicators to determine its place on the flight path 
In the next stage of the study the effectiveness of the method was evaluated. The evaluation was based on real measurements using the camera of the thermal imaging set installed in the aerodrome. Examples of use are presented in successive figures.

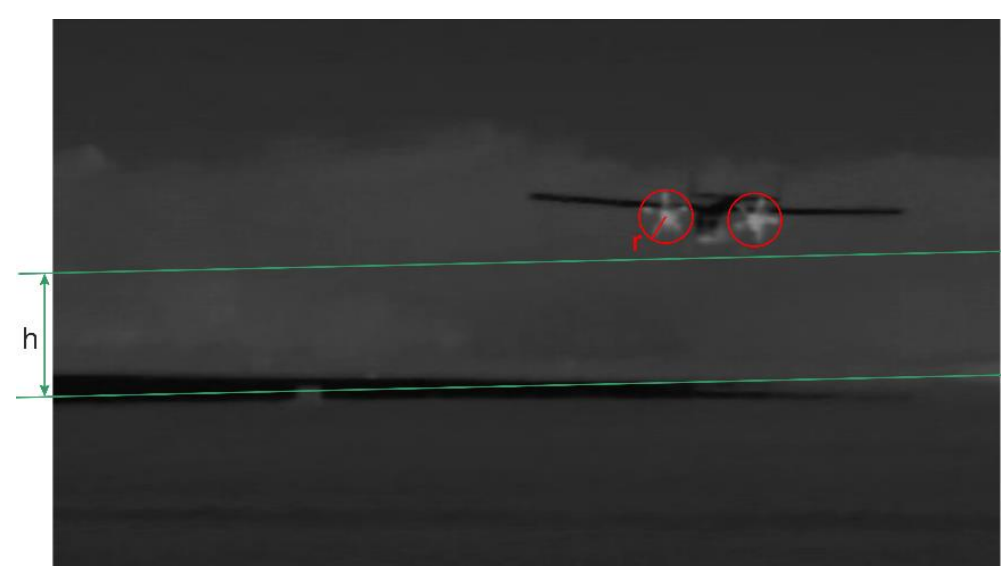

Fig. 11. Determining plane altitude over aerodrome — range $250 \mathrm{~m}$

$$
\frac{r}{h}=\frac{R}{H} ; \quad H=\frac{R * h}{r} ; \quad H \approx 6.6[\mathrm{~m}] .
$$

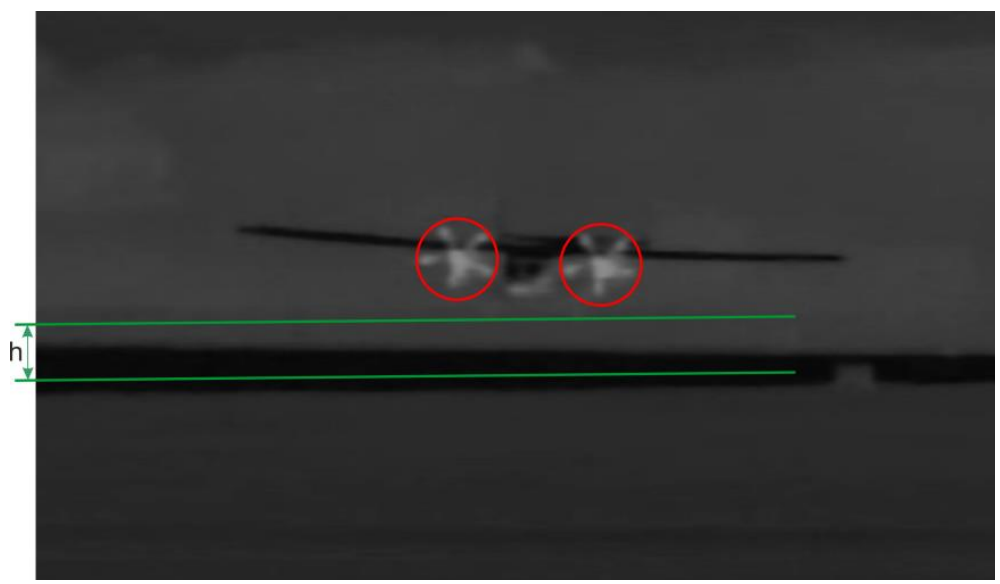

Fig. 12. Determining plane altitude over aerodrome — distance $20 \mathrm{~m}$

$$
\frac{r}{h}=\frac{R}{H} ; \quad H=\frac{R * h}{r} ; \quad H \approx 2[\mathrm{~m}] .
$$




\section{CONCLUSIONS}

It follows from the analysis of the literature that both in the case of unmanned and manned aerial vehicles the most air accidents occur during approach to landing. Therefore a lot of attention is paid to developing systems enhancing safety of this process. Use of optoelectronic devices in flight control systems, e.g. in the form of ground-based vision systems proves very beneficial. Placing cameras on the ground extends the range of possibilities and increases the effectiveness of such systems and provides independent operation of objects under control.

This article indicates a possibility of fast adaptation of aerial observation systems, operated in aerodromes and not directly connected with flight safety, to be used in support of this process. The results presented show occurrence of conditions and physical opportunities for the process to be realized both with vision systems as well as available infrared-based systems.

The concept of the presented flight control station was developed when measurements were made in connection with project No. O ROB 00460301 executed in 2012-2016, financed by the National Research and Development Center within the framework of the program OiB (Defense and Security).

\section{REFERENCES}

[1] Kong W., Zhou D., Zhang D., Vision-based Autonomous Landing system for Unmanned Aerial Vehicle: A Survey. Accessible, Multisensor Fusion and Information Integration for Intelligent Systems (MFI), 2014 International Conference [online], http://ieeexplore.ieee.org/ document/7279258/ [access 12.05.2016].

[2] Kong W., Zhang D., Wang X., Xian X., Zhang J., Autonomous Landing of an UAV with a Ground-Based Actuated Infrared Stereo Vision System, Intelligent Robots and Sys-tems (IROS), 2013 IEEE/RSJ International Conference, [online], http://lockdog.ru/files/pdf_lib/uav_ip [access 12.05.2016].

[3] Zhang D., Qi H., Wu X., Xie Y., Xu J., The Quadrotor Dynamic Modelling and Indoor Target Tracking Control Method, Mathematical Problems in Engineering Volume 2014, Article ID 637034, [online], http://dx.doi.org/10.1155/2014/637034 [access 12.05.2016].

[4] Kong W., Zhou D., Zhang Yu, Zhang D., Wang X., A ground-based optical system for au-tonomous landing of a fixed wing UAV, Intelligent Robots and Systems (IROS), 2014 IEEE/RSJ International Conference, [online], http://ieeexplore.ieee.org/ document/6943244/ [access 12.05.2016]. 
[5] Fossen T., Marine Craft Hydrodynamics and Motion Control, John Willey \& Sons, 2011.

[6] PTZ-35 MS, PTZ-50 MS, Installation and Operational Manual, FLIR Systems.

[7] Milewski S., Fundamental Limitations to Infrared Sensor Performance in Maritime Conditions [in Polish], III International Scientific and Technical Conference 'Marine Technology and Arms' NATCon, Gdynia 2009.

[8] Yilmaz A., Object tracking and activity recognition in video acquired using mobile cameras (a dissertation submitted in partial fulfillment of the requirements for the degree of Doctor of Philosophy at the University of Central Florida), Orlando 2004, [online], http://etd.fcla.edu/CF/CFE0000101/Yilmaz_Alper_200407_PhD.pdf [access 12.05.2016].

Received September 2016

Reviewed October 2017

Published 25.11.2017

\section{JACEK ZALEWSKI}

Polish Naval Academy

Śmidowicza 69 Str., 81-127 Gdynia, Poland

e-mail: j.zalewski@amw.gdynia.pl

\section{STANISŁAW MILEWSKI}

Polish Naval Academy

Śmidowicza 69 Str., 81-127 Gdynia, Poland

e-mail: s.milewski@amw.gdynia.pl

\section{MICHAL ZABLOTNY}

Polish Naval Academy

Śmidowicza 69 Str., 81-127 Gdynia, Poland

e-mail: m.zablotny@amw.gdynia.pl

\section{STRESZCZENIE}

Charakter i warunki misji statków powietrznych w operacjach wojskowych są specyficzne i trudne. Powoduje to konieczność zabezpieczenia ich działań w aspekcie kontroli sterowanego lub autonomicznego lotu, zwłaszcza podczas startów i lądowań.

Artykuł stanowi opis doświadczenia oraz próbę oceny przydatności kamer termowizyjnych do kontroli lotu statków powietrznych, szczególnie w obszarach lotnisk i torów podejściowych. 